•生物编目・

\title{
广东云开山国家级自然保护区鸟兽 红外相机调查初报
}

李林妙 ${ }^{1}$ 池辉云 ${ }^{2}$ 万雅琼 ${ }^{3}$ 周佳滨 ${ }^{1}$ 张礼标 $^{1}$ 何向阳 ${ }^{1}$ 黄文忠 ${ }^{1}$ 张伯军 ${ }^{2}$ 徐湛荣 ${ }^{2}$ 刘昌传 ${ }^{2}$ 赖任燕 ${ }^{2}$ 朱秀芳 ${ }^{2}$ 李友余 ${ }^{2}$ 李佳琦 $^{3^{*}}$ 陈金平 ${ }^{*}$

1 (广东省科学院动物研究所/广东省动物保护与资源利用重点实验室/广东省野生动物保护与利用公共实验室, 广州 510260) 2 (广东云开山省级自然保护区管理处, 广东茂名 525300)

3 (生态环境部南京环境科学研究所, 南京 210042)

摘要: 2017年1月至2019年9月, 我们在广东云开山国家级自然保护区3个观测样区布设61台红外相机, 对兽类和鸟 类多样性进行调查。共记录到野生兽类4目7科9种, 鸟类6目14科34种, 其中广东省新记录1种, 为蓝绿鹊(Cissa chinensis), 记录国家II级重点保护动物2种, 为原鸡(Gallus gallus)和白鸱(Lophura nycthemera)。相对多度较高的5 种兽类依次为赤腹松鼠(Callosciurus erythraeus)、赤鹿(Muntiacus vaginalis)、舀獾(Melogale moschata)、野猪(Sus scrofa)和果子狸(Paguma larvata), 相对多度较高的3种鸟类分别是紫啸冻(Myiophoneus caeruleus)、虎斑地鸫 (Zoothera dauma)和红嘴相思鸟(Leiothrix lutea)。通过对相对多度指数前三的鸟兽日活动节律观察分析, 共发现4 种典型昼行性动物(赤腹松鼠、紫啸鸫、虎斑地鸫和红嘴相思鸟)和1种典型夜行性动物(鼠獾)。赤麇日活动呈现两 个高峰时段, 分别为12:00-14:00和18:00-20:00。本研究评估了广东云开山国家级自然保护区部分兽类和鸟类资源 现状, 为保护区野生动物保护与管理提供了数据支持。

关键词: 兽类; 鸟类; 物种多样性; 红外相机监测; 云开山国家级自然保护区

\section{Camera-trapping survey on mammals and birds in the Guangdong Yunkaishan National Nature Reserve}

Linmiao $\mathrm{Li}^{1}$, Huiyun $\mathrm{Chi}^{2}$, Yaqiong $\mathrm{Wan}^{3}$, Jiabin $\mathrm{Zhou}^{1}$, Libiao Zhang ${ }^{1}$, Xiangyang $\mathrm{He}^{1}$, Wenzhong Huang ${ }^{1}$, Bojun Zhang ${ }^{2}$, Zhanrong $\mathrm{Xu}^{2}$, Changchuan $\mathrm{Liu}^{2}$, Renyan $\mathrm{Lai}^{2}$, Xiufang $\mathrm{Zhu}^{2}$, Youyu $\mathrm{Li}^{2}$, Jiaqi $\mathrm{Li}^{3 *}$, Jinping Chen $^{1^{*}}$

1 Guangdong Key Laboratory of Animal Conservation and Resource Utilization, Guangdong Public Laboratory of Wild Animal Conservation and Utilization, Institute of Zoology, Guangdong Academy of Sciences, Guangzhou 510260

2 Guangdong Yunkaishan Provincial Nature Reserve Administration Bureau, Maoming, Guangdong 525300

3 Nanjing Institute of Environmental Science, Ministry of Ecology and Environment, Nanjing 210042

\begin{abstract}
In order to document the wildlife resources in the Guangdong Yunkaishan National Nature Reserve, 61 infrared cameras were used to monitor mammals and birds at 3 observation plots from January 2017 to September 2019. Based on the camera data, we found 9 mammal species belonging to 4 orders and 7 families, and 34 bird species belonging to 6 orders and 14 families. There were two species listed as Class II National Protected Wildlife in China: the red jungle fowl (Gallus gallus) and silver pheasant (Lophura nycthemera). Common green magpie (Cissa chinensis) was a new recorded species in Guangdong Province. The five most abundant mammal species with the highest relative abundance index (RAI) were Pallas's squirrel (Callosciurus erythraeus), red muntjac (Muntiacus vaginalis), Chinese ferret-badger (Melogale moschata), wild boar (Sus scrofa) and palm civet (Paguma larvata), respectively. In addition, the three most abundant bird species with the highest RAI were blue whistling thrush (Myiophoneus caeruleus), scaly thrush (Zoothera dauma) and red billed leiothrix bird (Leiothrix lutea), respectively. The activity rhythm analysis of
\end{abstract}

收稿日期: 2020-03-19; 接受日期: 2020-07-04

基金项目: 生态环境部生物多样性保护专项(2110404)和广东省科学院科技发展专项(2018GDASCX-0107)

* 共同通讯作者 Co-authors for correspondence. E-mail: 99357107@qq.com; chenjp@giabr.gd.cn 
the three dominant mammals and three dominant bird species revealed that the Chinese ferret-badger was a diurnal animal, while the three birds (blue whistling thrush, scaly thrush and red billed leiothrix bird) and one mammal (Pallas's squirrel) were nocturnal animals. The daily activity rhythm of the red muntjac showed two active peaks at 12:00-14:00 and 18:00-20:00. Our results provide important data on mammal and bird diversity in Guangdong Yunkaishan National Nature Reserve, which will be beneficial for wildlife protection and management in the reserve.

Key words: mammals; birds; species diversity; camera-trapping; Yunkaishan National Nature Reserve

广东云开山国家级自然保护区(以下简称云开 山保护区) 地理位置为 $111^{\circ} 08^{\prime}-111^{\circ} 26^{\prime} \mathrm{E}$, $22^{\circ} 13^{\prime}-22^{\circ} 23^{\prime} \mathrm{N}$, 总面积 $125.11 \mathrm{~km}^{2}$ 。地跨信宜、高 州两市, 东北与茂名林洲顶省级自然保护区相邻。 地形由云开山主峰及其附近数十座海拔逾千米的 山峰组成, 最高海拔为大田顶 $(1,704 \mathrm{~m})$, 年平均气 温约为 $18^{\circ} \mathrm{C}$, 年降水量约 $2,300-2,600 \mathrm{~mm}$ (陈锡沐 等, 1990), 属于南亚热带季风气候区。保护区及其 周边是粤西及周边的大部分河流的发源地。

保护区内不仅保存有大面积完整的次生南亚 热带常绿阔叶林和沟谷雨林, 而且也蕴藏着丰富的 野生动物资源。2015年10月在中国自然保护区标本 资源共享平台 (http://www.papc.cn/html/report/ 15100005-1.htm)公布的云开山保护区的科考数据 显示：保护区共记录到昆虫1,500多种，鱼纲4目15 科43种, 陆生野生脊椎动物337种(其中哺乳纲8目 24 科 56 种，鸟纲 16 目 48 科 196 种，爬行纲 3 目 16 科 59 种, 两栖纲 2 目 8 科 26 种), 国家I级重点保护动物 8 种, 国家 II 级重点保护动物 30 种。虽然记录的野生动物 种类多样性丰富, 但尚缺乏野生动物种群分布以及 多样性变化资料, 且未见文献报道对动物种类与数 量的系统性调查。

传统的鸟兽调查方法, 比如样线法、样点法、 记录足迹或粪便痕迹、网捕和陷阱笼捕等, 易使目 标动物产生强烈应激反应(田成等, 2018), 难以对种 群数量较低或活动隐蔽的物种有效地进行监测和 评估(O’Connell et al, 2011)。而红外相机技术具有准 确性、长期性、低干扰、非损伤性等优点(李晟等, 2014), 能够获取野生动物的行为、种群、生境利用 和群落的相关信息, 为评估野生动物的丰富度与活 动节律提供重要的证据(Tobler et al, 2009; 穆君等, 2019)。因此, 本研究利用红外相机对云开山保护区 内兽类和鸟类进行监测, 以期深入了解该保护区内 野生动物资源状况, 为其保护和管理工作提供科学
依据。

\section{研究方法}

\section{1 相机布设}

根据经纬度将保护区划分为 $1 \mathrm{~km} \times 1 \mathrm{~km}$ 的公 里网格, 结合保护区内野生动物和人为活动干扰等 因素, 选取3个观测样区(图1), 其中1号和 2 号观测 样区选取20个连续的网格, 3 号观测样区选取19个 连续网格作为抽样网格, 在每个网格中心区域选择 合适的位置放置1台红外相机，不同网格之间的两 台相机间隔至少 $500 \mathrm{~m}$ (李佳琦等, 2018)。调查采用 的红外相机型号为猎科Ltl-6210、Ltl-6511和东方红 鹰E1B, 相机功能参数统一设置, 包括日期、拍摄模 式(拍照 + 录像)、拍摄间隔 $(1 \mathrm{~s}) 、$ 连拍(3张)、视频 (10 s)等, 并对每个相机位点的GPS信息(经度、纬度 和海拔)和生境进行记录(附录1)。监测时间为2017 年1月至2019年9月, 期间每隔5-6个月更换电池和 存储卡。

\section{2 数据处理}

采集的红外相机数据和相机位置信息上传到 哺乳类生物多样 性观测数据库 (http://114.251.10.194/html5/mammal/login), 通过此 数据库对本次采集的照片进行物种鉴定和分类。兽 类分类依据《中国哺乳动物多样性(第二版)》(蒋志 刚等, 2017), 鸟类分类依据《中国鸟类分类与分布名 录(第三版)》(郑光美, 2017); 濒危等级参考IUCN红 色名录(https://www.iucnredlist.org/)和《中国脊椎动 物红色名录》 (蒋志刚等, 2016); 国家重点保护等级 参考1989年颁布的《国家重点保护野生动物名录》。

同一位点30 min内重复出现的同一物种(照片 或视频)记录为 1 张独立有效照片( O’Brien et al, 2003), 单台红外相机持续工作 $24 \mathrm{~h}$ 记为 1 个有效相 机工作日, 即为一个捕获日(陈声文等, 2016; 袁景 西等, 2016)。使用相对多度指数(relative abundance 


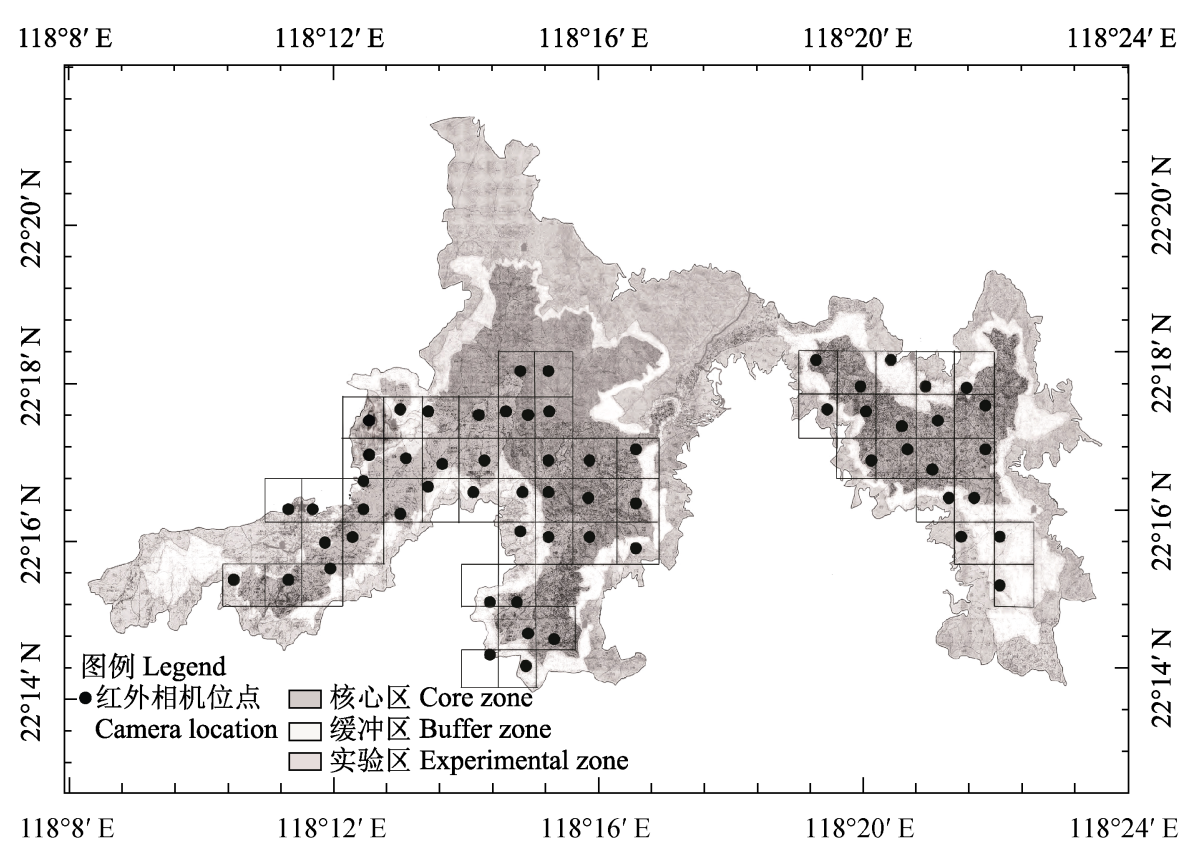

图1 广东云开山国家级自然保护区红外相机布设位点

Fig. 1 Camera-trapping sites in the Guangdong Yunkaishan National Nature Reserve

index, RAI)评价不同物种的种群差异(杨雄威等, 2020), 以某一时间段内相对多度指数(time-period relative abundance index, TRAI)来分析物种日活动 节律, 计算公式为: RAI = (物种独立有效照片数 $/$ 相 机总工作日 $) \times 100, \mathrm{TRAI}=($ 物种 $i$ 在 $j$ 时间段内出现 的有效照片数/物种 $i$ 的有效照片总数 $) \times 100$ 。

\section{2 结果}

61 个位点累计监测37,638个相机工作日, 共获 得独立有效物种照片 9,440 张, 其中兽类 2,858 张, 鸟类 1,468 张, 家畜 723 张, 人员和无法识别物种 4,391 张, 分别占独立有效照片总数的 $30.28 \%$ 、

15.55\%、7.66\%和 $46.51 \%$ 。

共鉴定野生兽类9种, 隶属 4 目7科; 鸟类 34 种, 隶属6目14科(附录2, 附录3)。记录国家 II 级重点保 护野生动物 2 种, 即原鸡 (Gallus gallus) 和白閜 (Lophura nycthemera)。被《中国脊椎动物红色名录》 评估为易危 (VU) 的有 1 种, 即豹猫 (Prionailurus bengalensis); 被评估为近危(NT)的有10种, 分别为 赤鹿 (Muntiacus vaginalis)、果子狸 (Paguma larvata)、鼠獾 (Melogale moschata)、黄腹鼠(Mustela kathiah)、红腿长吻松鼠(Dremomys pyrrhomerus),
原鸡、中华鹤鸪(Francolinus pintadeanus)、蓝绿鹊 (Cissa chinensis)、画眉(Garrulax canorus)和黑冠鳽 (Gorsachius melanolophus), 其中蓝绿鹊为广东省新 记录种。被IUCN红色名录评估为易危(VU)的有1种, 即绿翅金鸠(Chalcophaps indica) (附录2)。

物种相对多度指数计算结果表明(附录2), 兽 类中相对多度较高的为赤腹松鼠 (Callosciurus erythraeus, RAI = 1.61)、赤鹿(RAI = 1.51)、鼠獾(RAI $=1.50)$ 、野猪 $($ Sus scrofa, RAI = 0.79) 和果子狸 $(\mathrm{RAI}$ $=0.27$ ), 鸟类为紫啸冻 (Myiophoneus caeruleus, RAI $=1.37$ 、虎斑地冻 (Zoothera dauma, RAI = 0.98) 和红 嘴相思鸟 (Leiothrix lutea, RAI = 0.89)。

对保护区RAI值较高的3种兽类(赤腹松鼠、赤 鹿、鼠由獾)和3种鸟类(紫啸鸫、虎斑地冻、红嘴相思 鸟)进行日活动分析, 结果表明(图2): 赤腹松鼠的 日活动主要集中在6:00-8:00和16:00-18:00; 赤鹿的 日活动主要集中在12:00-14:00和18:00-20:00; 鼠獾 为典型的夜行动物, 主要活动时间为 4:00-6:00和 22:00-24:00。三种鸟类为昼行性活动动物, 活动规 律相似, 其中紫啸冻日活动主要集中在8:00-10:00 和16:00-18:00, 而虎斑地冻和红嘴相思鸟的日活动 主要集中在10:00-12:00和14:00-16:00。 


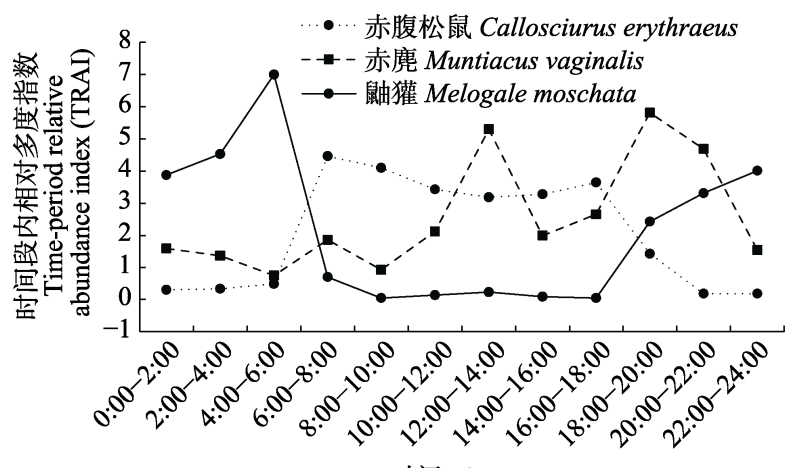

时间 Time

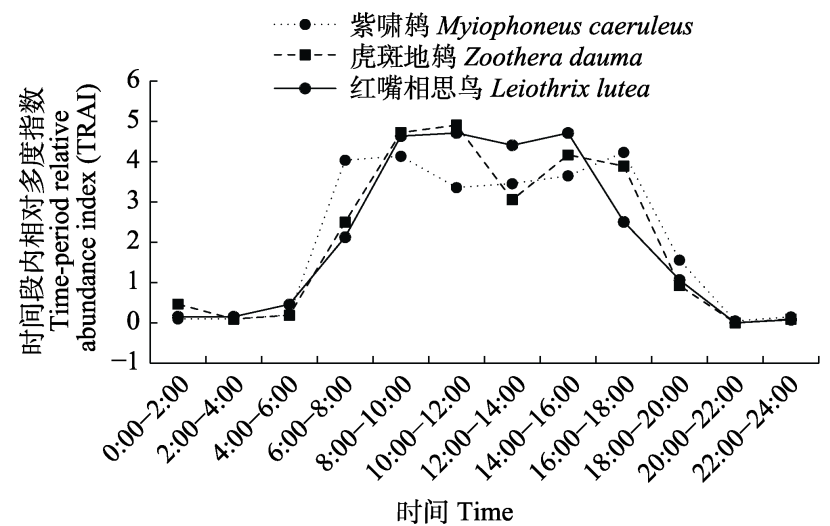

图2 广东云开山国家级自然保护区主要物种日活动节律 Fig. 2 Daily activity rhythm of main species in the Guangdong Yunkaishan National Nature Reserve

\section{3 讨论}

根据本次红外相机监测数据, 初步获得了云开 山保护区大中型兽类和林下活动鸟类的物种名录 (附录2)。此次调查只记录到9种野生兽类, 与2015 年在中国自然保护区标本资源共享平台公布的数 据相比, 未拍到国家I级保护动物豹 (Panthera pardus)、中华穿山甲(Manis pentadactyla)和云豹 (Neofelis nebulosa), 以及国家II级保护动物大灵猫 (Viverra zibetha)、小灵猫(Viverricula indica)、金猫 (Catopuma temminckii) 、斑 林 狸 (Prionodon pardicolor), 可能跟相机安装位点和位置有关, 也 可能因其数量极少, 相机未能覆盖到它们的活动区 域, 但豹和云豹在广东南岭区域的保护区内也未记 录到(肖治术等, 2014; 蔡玉生等, 2016; 袁景西等, 2016), 说明这些大型兽类种群在华南地区已受到 严重威胁。同时发现, 野猪、赤鹿、豹猫种群相对 多度较高, 这可能与保护区内缺少大型食肉动物有 关, 再次证明保护区内大型兽类已极少。本次调查 发现人类活动(捕猎、放牧、旅游、挖药材等)频繁(附
录2), 对野生动物的栖息地产生了明显干扰，进而 影响了野生动物的生存。因此, 人为干扰可能仍是 威胁当地野生动物生存的重要因素。

通过对保护区内主要兽类和鸟类日活动分析, 发现赤腹松鼠具有晨昏活动规律, 可能与动物适应 当地环境和应对食物资源季节性变化所采取的策 略有关(汪国海, 2016 ${ }^{(1)}$; 穆君等, 2019)。研究发现, 大多数偶蹄类具有晨昏活动节律 $($ 刘振生, 2003; 汪 国海等, 2015), 但本研究发现赤鹿的活动高峰主要 集中在12:00-14:00和18:00-20:00, 赤鹿的这一活动 节律与保护区内偶蹄类的家牛和野猪 6:00-8:00的 活动频繁相关, 这可能与它们均以植食性食物为主, 从而存在食物竞争关系有关。鼠獾在夜间的活动规 律与刘佳等(2018)的研究结果一致, 这样的活动策 略可以获得更多食物，因为䶅獾在夜间可以捕食老 鼠、昆虫等，同时有利于隐蔽或身朵避天敌，降低与 晨昏型肉食动物的相遇和被捕食的风险(刘宇等, 2019)。因此云开山保护区野生动物长期适应当地的 气候因子、食物季节性变化、繁殖行为、天敌以及 人为干扰等因素影响，形成了固有的生活节律。

云开山保护区具有相对独特的动物区系特征, 与粤北和粤东区别较大, 而更接近广西和越南, 因 此云开山保护区具有特别的物种分布, 例如北树鼠 (Tupaia belangeri)和原鸡。北树鼠作为广东新记录 种是在广东阳春被发现(卢学理和王新财, 2017), 而 本次调查有 24 个位点均拍到北树䳔 $(\mathrm{RAI}=0.23)$, 表明保护区内有稳定的种群存在，阳春也属于云开 山脉，说明北树獡具有较广的栖息地范围; 而广东 原鸡是吴诗宝团队1998年在云开山保护区调查中 首次发现(吴诗宝，2000)，其主要分布在粤西地区， 面积最大的栖息地是信宜、高州、阳春3个区域，且 数量最多, 其种群数量有 650-700只(吴诗宝等, 2002), 而本次调查期间有 14 个相机位点多次拍到 原鸡，独立照片数22张，海拔分布在427-927 m, 表 明目前广东原鸡在保护区有稳定的种群存在，建议 继续加强对这些特有野生动物的保护，以利于这些 动物种群的复壮。

综上所述, 本研究首次利用红外相机对云开 山保护区兽类和鸟类进行连续监测，获得了大量影

(1) 汪国海 (2016) 红外相机技术在广西花坪和猫儿山保护区动物监测 中的应用比较. 硕士学位论文, 广西师范大学, 桂林. 
像资料, 为系统揭示云开山保护区大中型兽类和地 栖鸟类多样性提供了重要参考。在后续的野外工作 中, 建议增加监测位点数量, 加大调查范围, 建立 长期监测机制, 不断补充更新保护区的野生动物本 底数据。

致谢：本研究得到广东云开山国家级自然保护区管 理人员与护林员的大力支持与协作; 广东省科学院 动物研究所江海英、林立波、黄铭威、莫大颖、黄 涁、王河林、周晓珊等参与野外工作与数据处理, 在 此一并致谢!

\section{参考文献}

Cai YS, Gong YN, Lu XL, Xiao ZS, Wang XC (2016) Camera trap survey of mammal diversity in Nanling Forests. Ecological Science, 35(2), 57-61. (in Chinese with English abstract) [蔡玉生, 龚粤宁, 卢学理, 肖治术, 王新财 (2016) 南岭森林哺乳动物多样性的红外相机监测. 生态 科学, 35(2), 57-61.]

Chen SW, Yu JP, Chen XN, Shen XL, Li S, Ma KP (2016) Camera-trapping survey on the diversity of mammal and pheasant species in Gutianshan National Nature Reserve, Zhejiang Province. Acta Theriologica Sinica, 36, 292-301. (in Chinese with English abstract) [陈声文, 余建平, 陈小 南, 申小莉, 李晟, 马克平 (2016) 利用红外相机网络调 查古田山自然保护区的兽类及雉类多样性. 兽类学报, 36, 292-301.]

Chen XM, Xiao MY, Feng ZJ (1990) An investigation of plant resources on Dawu Mountain. Journal of South China Agriculture University, 11, 81-84. (in Chinese with English abstract) [陈锡沐, 肖绵韵, 冯志坚 (1990) 大雾岭的植物 资源. 华南农业大学学报, 11, 81-84.]

Jiang ZG, Jiang JP, Wang YZ, Zhang E, Zhang YY, Li LL, Xie F, Cai B, Cao L, Zheng GM, Dong L, Zhang ZW, Ding P, Luo ZH, Ding CQ, Ma ZJ, Tang SH, Cao WX, Li CW, Hu HJ, Ma Y, Wu Y, Wang YX, Zhou KY, Liu SY, Chen YY, Li JT, Feng ZJ, Wang Y, Wang B, Li C, Song XL, Cai L, Zang CX, Zeng Y, Meng ZB, Fang HX, Ping XG (2016) Red List of China's Vertebrates. Biodiversity Science, 24, 500-551. (in Chinese and in English) [蒋志刚, 江建平, 王 跃招, 张鹗, 张雁云, 李立立, 谢锋, 蔡波, 曹亮, 郑光 美, 董路, 张正旺, 丁平, 罗振华, 丁长青, 马志军, 汤宋 华, 曹文宣, 李春旺, 胡慧建, 马勇, 吴毅, 王应祥, 周开 亚, 刘少英, 陈跃英, 李家堂, 冯祚建, 王燕, 王斌, 李 成, 宋雪琳, 蔡蕾, 葴春金金, 曾岩, 孟智斌, 方红霞, 平晓 鸽 (2016) 中国脊椎动物红色名录. 生物多样性, 24, 500-551.]

Jiang ZG, Liu SY, Wu Y, Jiang XL, Zhou KY (2017) China’s mammal diversity (2nd edition). Biodiversity Science, 25, 886-895. (in Chinese with English abstract) [蒋志刚, 刘少 英, 吴毅, 蒋学龙, 周开亚 (2017) 中国哺乳动物多样性 (第2版). 生物多样性, 25, 886-895.]

Li JQ, Xu HG, Wan YQ, Sun JX, Li S, Cai L (2018) Progress in construction of China mammal diversity observation network (China BON-Mammals). Journal of Ecology and Rural Environment, 34, 12-19. (in Chinese with English abstract) [李佳琦, 徐海根, 万雅琼, 孙佳欣, 李晟, 蔡蕾 (2018) 全国哺乳动物多样性观测网络建设进展. 生态与 农村环境学报, 34, 12-19.]

Li S, Wang DJ, Xiao ZS, Li XH, Wang TM, Feng LM, Wang $Y$ (2014) Camera-trapping in wildlife research and conservation in China: Review and outlook. Biodiversity Science, 22, 685-695. (in Chinese with English abstract) [李 晟, 王大军, 肖治术, 李欣海, 王天明, 冯利民, 王云 (2014) 红外相机技术在我国野生动物研究与保护中的应 用与前景. 生物多样性, 22, 685-695.]

Liu J, Lin JZ, Li SQ, Li YB, Yao ZM, Wei LM, Tan CJ, Zhou QH, Huang CM (2018) Preliminary investigation for mammal and bird resources using infrared camera traps in Maolan National Nature Reserve, Guizhou. Acta Theriologica Sinica, 38, 323-330. (in Chinese with English abstract) [刘佳, 林建忠, 李生强, 李友邦, 姚正明, 魏鲁 明, 谭成江, 周岐海, 黄乘明 (2018) 利用红外相机对贵 州茂兰自然保护区兽类和鸟类资源的初步调查. 兽类学 报, 38, 323-330.]

Liu Y, Miao H, Jiang GL, Yao CX, Wang ZH, Wang F, Jiang ZC, Zhang ZZ, Liu DJ, Chen MY (2019) Analysis of daily activity rhythm and activity pattern of four species of mammals in Gulinqing Provincial Nature Reserve, Yunnan. Chinese Journal of Wildlife, 40, 832-839. (in Chinese with English abstract) [刘宇, 缪华, 蒋桂莲, 姚冲学, 王智红, 王方, 姜志诚, 张志忠, 刘德军, 陈明勇 (2019) 云南古 林箐省级自然保护区四种哺乳动物日活动节律及活动模 式分析. 野生动物学报, 40, 832-839.]

Liu ZS (2003) Ecological Research on Red Muntjac (Muntiacus muntjak) in Hainan Datian National Nature Reserve. PhD dissertation, Northeast Forestry University, Harbin. (in Chinese with English abstract) [刘振生 (2003) 海南大田国家级自然保护区赤鹿(Muntiacus muntjak)生态 学研究. 博士学位论文, 东北林业大学, 哈尔滨.]

Lu XL, Wang XC (2017) The distribution of Tupaia belangeri in Guangdong Province. Forestry and Environmental Science, 33, 98-100. (in Chinese with English abstract) [卢 学理, 王新财 (2017) 广东省北树鼠分布. 林业与环境科 学, 33, 98-100.]

Mu J, Wang JJ, Zhang L, Li YB, Li ZM, Su HJ (2019) Field monitoring using infrared cameras and activity rhythm analysis on mammals and birds in Xishui National Nature Reserve, Guizhou, China. Biodiversity Science, 27, 683-688. (in Chinese with English abstract) [穆君, 王娇娇, 
张雷, 李云波, 李筑眉, 粟海军 (2019) 贵州习水国家级 自然保护区红外相机鸟兽监测及活动节律分析. 生物多 样性, 27, 683-688.]

O’Brien TG, Kinnaird MF, Wibisono HT (2003) Crouching tigers, hidden prey: Sumatran tiger and prey populations in a tropical forest landscape. Animal Conservation, 6, 131-139.

O’Connell AF, Nichols JD, Karanth KU (2011) Camera Traps in Animal Ecology: Methods and Analyses. SpringerVerlag, New York.

Tian C, Li JQ, Yang XY, Yu L, Yuan D, Li YX (2018) Preliminary surveys of wild animals using infrared camera in Wanglang National Nature Reserve, Sichuan Province. Biodiversity Science, 26, 620-626. (in Chinese with English abstract) [田成, 李俊清, 杨旭显, 余鳞, 袁丹, 黎运喜 (2018) 利用红外相机技术对四川王朗国家级自然保护区 野生动物物种多样性的初步调查. 生物多样性, 26, 620-626.]

Tobler MW, Carrillo-Percastegui SE, Powell G (2009) Habitat use, activity patterns and use of mineral licks by five species of ungulate in south-eastern Peru. Journal of Tropical Ecology, 25, 261-270.

Wang GH, Shi ZP, Li SQ, Zhou QH (2015) Activity pattern of Muntiacus muntjak revealed with infrared camera. Journal of Guangxi Normal University (Natural Science Edition), 33, 117-122. (in Chinese with English abstract) [汪国海, 施泽攀, 李生强, 周岐海 (2015) 基于红外相机技术的赤 鹿活动模式分析. 广西师范大学学报(自然科学版), 33, 117-122.]

Wu SB (2000) Gallus gallus was discovered in Dawuling Nature Reserve, Guangdong. Chinese Journal of Wildlife, 21, 46. (in Chinese) [吴诗宝 (2000) 广东大雾岭自然保护 区首次发现原鸡. 野生动物学报, 21, 46.]

Wu SB, Yuan XC, Ke YY, Chen H (2002) Preliminary investigation on the distribution and habitat of red jungle fowl (Gallus gallus) in Guangdong Province. Chinese
Journal of Zoology, 37(3), 30-33. (in Chinese with English abstract) [吴诗宝, 袁喜才, 柯亚永, 陈海 (2002) 广东省 原鸡种群数量、分布及栖息地现状的初步调查. 动物学杂 志, 37(3), 30-33.]

Xiao ZS, Wu LF, Tang LF, Lu XL, Huang ZL, Ye WH, Huang XQ (2014) Camera trap survey of mammals and birds in Dinghushan forest dynamics plot, Southern China. Biodiversity Science, 22, 823-825. (in Chinese) [肖治术, 吴林芳, 唐林芳, 卢学理, 黄忠良, 叶万辉, 黄小群 (2014) 运用红外相机对鼎湖山森林动态监测样地鸟兽的 初步调查. 生物多样性, 22, 823-825.]

Yang XW, Wu AK, Zou QX, Li GR, Zhang MM, Hu CS, Su HJ (2020) Field monitoring on mammals and birds using infrared cameras in Mayanghe National Nature Reserve, Guizhou, China. Biodiversity Science, 28, 219-225. (in Chinese with English abstract) [杨雄威, 吴安康, 邹启先, 李光容, 张明明, 胡灿实, 粟海军 (2020) 贵州麻阳河国 家级自然保护区红外相机鸟兽监测. 生物多样性, 28, 219-225.]

Yuan JX, Zhang CY, Xie WH, Huang XQ, Xiao ZS (2016) Using camera traps to investigate mammal and bird diversity in the Jiulianshan National Nature Reserve, Jiangxi Province. Acta Theriologica Sinica, 36, 367-372. (in Chinese with English abstract) [袁景西, 张昌友, 谢文华, 黄小群, 肖治术 (2016) 利用红外相机技术对九连山国 家级自然保护区兽类和鸟类资源的初步调查. 兽类学报, 36, 367-372.]

Zheng GM (2017) A Checklist on the Classification and Distribution of the Birds of China, 3rd edn. Science Press, Beijing. (in Chinese) [郑光美 (2017) 中国鸟类分类与分 布名录(第三版). 科学出版社, 北京.]

(责任编委：肖治术 责任编辑：问文杰)

\section{附录 Supplementary Material}

附录1 广东云开山国家级自然保护区红外相机位点信息

Appendix 1 The information of infrared camera installation location in the Guangdong Yunkaishan National Nature Reserve http://www.biodiversity-science.net/fileup/PDF/2020103-1.pdf

\section{附录2 广东云开山国家级自然保护区红外相机调查记录到的兽类和鸟类物种名录}

Appendix 2 The list of mammals and birds captured by camera-trapping in the Guangdong Yunkaishan National Nature Reserve http://www.biodiversity-science.net/fileup/PDF/2020103-2.pdf

\section{附录3 广东云开山国家级自然保护区红外相机调查中记录到的部分兽类和鸟类物种照片}

Appendix 3 Photographs of mammal and bird species recorded by the camera-trapping in the Guangdong Yunkaishan National Nature Reserve

http://www.biodiversity-science.net/fileup/PDF/2020103-3.pdf 
李林妙, 池辉云, 万雅琼, 周佳滨, 张礼标, 何向阳, 黄文忠, 张伯军, 徐湛荣, 刘昌传, 赖任燕, 朱秀芳, 李友余, 李佳琦, 陈金平 (2020) 广东云开山国家级自然保护区鸟兽 红外相机调查初报. 生物多样性, 28, 1154-1159. http://www.biodiversity-science.net/CN/10.17520/biods.2020103

附录1 广东云开山国家级自然保护区红外相机位点信息

Appendix 1 The information of infrared camera installation location in the Guangdong Yunkaishan National Nature Reserve

\begin{tabular}{|c|c|c|c|c|c|c|c|c|}
\hline $\begin{array}{c}\text { 序号 } \\
\text { Number }\end{array}$ & $\begin{array}{l}\text { 相机编号 } \\
\text { Camera ID }\end{array}$ & $\begin{array}{c}\text { 经度 } \\
\text { Longitude (E) }\end{array}$ & $\begin{array}{c}\text { 纬度 Latitude } \\
(\mathrm{N})\end{array}$ & $\begin{array}{c}\text { 海拔 } \\
\text { Altitude (m) }\end{array}$ & $\begin{array}{c}\text { 生境 } \\
\text { Habitat }\end{array}$ & $\begin{array}{c}\text { 累积工作日 } \\
\text { Accumulated } \\
\text { camera days (d) }\end{array}$ & $\begin{array}{c}\text { 有效照片数 Number of } \\
\text { independent images }\end{array}$ & $\begin{array}{c}\text { 拍摄物种数 Captured } \\
\text { species }\end{array}$ \\
\hline 1 & 44004-11-1-E12-01 & $111^{\circ} 10^{\prime} 27^{\prime \prime}$ & $22^{\circ} 15^{\prime} 34^{\prime \prime}$ & 1,188 & 兽路 & 760 & 159 & 12 \\
\hline 2 & 44004-11-1-F10-01 & $111^{\circ} 11^{\prime} 38^{\prime \prime}$ & $22^{\circ} 16^{\prime} 23^{\prime \prime}$ & 990 & 兽路 & 663 & 157 & 11 \\
\hline 3 & 44004-11-1-F12-01 & $111^{\circ} 11^{\prime} 35^{\prime \prime}$ & $22^{\circ} 15^{\prime} 42^{\prime \prime}$ & 1,250 & 兽路 & 697 & 186 & 9 \\
\hline 4 & 44004-11-1-G10-01 & $111^{\circ} 12^{\prime} 11^{\prime \prime}$ & $22^{\circ} 16^{\prime} 35^{\prime \prime}$ & 1,220 & 常绿、落叶阔叶混交林 & 765 & 333 & 12 \\
\hline 5 & 44004-11-1-G11-01 & $111^{\circ} 11^{\prime} 60^{\prime \prime}$ & $22^{\circ} 16^{\prime} 07^{\prime \prime}$ & 1,181 & 兽路 & 620 & 368 & 12 \\
\hline 6 & 44004-11-1-G12-01 & $111^{\circ} 12^{\prime} 20^{\prime \prime}$ & $22^{\circ} 15^{\prime} 51^{\prime \prime}$ & 1,440 & 兽路 & 746 & 166 & 14 \\
\hline 7 & 44004-11-1-H08-01 & $111^{\circ} 12^{\prime} 42^{\prime \prime}$ & $22^{\circ} 17^{\prime} 57^{\prime \prime}$ & 1,420 & 常绿、落叶阔叶混交林 & 635 & 265 & 16 \\
\hline 8 & 44004-11-1-H09-01 & $111^{\circ} 12^{\prime} 39^{\prime \prime}$ & $22^{\circ} 17^{\prime} 03^{\prime \prime}$ & 1,430 & 兽路 & 755 & 63 & 6 \\
\hline 9 & 44004-11-1-H10-01 & $111^{\circ} 12^{\prime} 39^{\prime \prime}$ & $22^{\circ} 16^{\prime} 48^{\prime \prime}$ & 1,440 & 兽路 & 737 & 64 & 9 \\
\hline 10 & 44004-11-1-H10-02 & $111^{\circ} 12^{\prime} 25^{\prime \prime}$ & $22^{\circ} 16^{\prime} 19^{\prime \prime}$ & 1,437 & 兽路 & 322 & 112 & 6 \\
\hline 11 & 44004-11-1-H11-01 & $111^{\circ} 12^{\prime} 09^{\prime \prime}$ & $22^{\circ} 16^{\prime} 07^{\prime \prime}$ & 1,269 & 山坡 & 920 & 195 & 10 \\
\hline 12 & 44004-11-1-I08-01 & $111^{\circ} 13^{\prime} 16^{\prime \prime}$ & $22^{\circ} 17^{\prime} 54^{\prime \prime}$ & 1,430 & 兽路 & 673 & 98 & 10 \\
\hline 13 & 44004-11-1-I09-01 & $111^{\circ} 13^{\prime} 09^{\prime \prime}$ & $22^{\circ} 17^{\prime} 12^{\prime \prime}$ & 1,610 & 常绿、落叶阔叶混交林 & 260 & 71 & 13 \\
\hline 14 & 44004-11-1-I10-01 & $111^{\circ} 13^{\prime} 11^{\prime \prime}$ & $22^{\circ} 16^{\prime} 12^{\prime \prime}$ & 1,174 & 山脊 & 780 & 77 & 7 \\
\hline 15 & 44004-11-1-J08-01 & $111^{\circ} 13^{\prime} 44^{\prime \prime}$ & $22^{\circ} 17^{\prime} 48^{\prime \prime}$ & 1,290 & 水塘 & 372 & 53 & 8 \\
\hline 16 & 44004-11-1-J09-01 & $111^{\circ} 13^{\prime} 24^{\prime \prime}$ & $22^{\circ} 17^{\prime} 26^{\prime \prime}$ & 1,520 & 兽路 & 444 & 16 & 4 \\
\hline 17 & 44004-11-1-J10-01 & $111^{\circ} 13^{\prime} 25^{\prime \prime}$ & $22^{\circ} 16^{\prime} 35^{\prime \prime}$ & 1,261 & 兽路 & 819 & 102 & 11 \\
\hline
\end{tabular}


李林妙, 池辉云, 万雅琼, 周佳滨, 张礼标, 何向阳, 黄文忠, 张伯军, 徐湛荣, 刘昌传, 赖任燕, 朱秀芳, 李友余, 李佳琦, 陈金平 (2020) 广东云开山国家级自然保护区鸟兽 红外相机调查初报. 生物多样性, 28, 1154-1159. http://www.biodiversity-science.net/CN/10.17520/biods.2020103

\begin{tabular}{|c|c|c|c|c|c|c|c|c|}
\hline 18 & 44004-11-1-K08-01 & $111^{\circ} 14^{\prime} 03^{\prime \prime}$ & $22^{\circ} 17^{\prime} 34^{\prime \prime}$ & 1,360 & 兽路 & 518 & 144 & 10 \\
\hline 19 & 44004-11-1-K10-01 & $111^{\circ} 14^{\prime} 17^{\prime \prime}$ & $22^{\circ} 16^{\prime} 33^{\prime \prime}$ & 1,088 & 兽路 & 642 & 284 & 16 \\
\hline 20 & 44004-11-1-L07-01 & $111^{\circ} 14^{\prime} 40^{\prime \prime}$ & $22^{\circ} 18^{\prime} 06^{\prime \prime}$ & 1,400 & 溪边 & 914 & 91 & 11 \\
\hline 21 & 44004-11-1-L08-01 & $111^{\circ} 15^{\prime} 15^{\prime \prime}$ & $22^{\circ} 17^{\prime} 45^{\prime \prime}$ & 1,232 & 山坡 & 847 & 376 & 14 \\
\hline 22 & 44004-11-1-L08-02 & $111^{\circ} 14^{\prime} 31^{\prime \prime}$ & $22^{\circ} 17^{\prime} 58^{\prime \prime}$ & 1,360 & 山坡 & 445 & 99 & 10 \\
\hline 23 & 44004-11-2-K12-01 & $111^{\circ} 14^{\prime} 14^{\prime \prime}$ & $22^{\circ} 15^{\prime} 16^{\prime \prime}$ & 1,043 & 溪边 & 790 & 132 & 10 \\
\hline 24 & 44004-11-2-K14-01 & $111^{\circ} 14^{\prime} 26^{\prime \prime}$ & $22^{\circ} 14^{\prime} 44^{\prime \prime}$ & 1,116 & 兽路 & 947 & 51 & 7 \\
\hline 25 & 44004-11-2-L09-01 & $111^{\circ} 14^{\prime} 58^{\prime \prime}$ & $22^{\circ} 17^{\prime} 01^{\prime \prime}$ & 1,183 & 兽路 & 956 & 407 & 14 \\
\hline 26 & 44004-11-2-L10-01 & $111^{\circ} 15^{\prime} 05^{\prime \prime}$ & $22^{\circ} 16^{\prime} 37^{\prime \prime}$ & 1,247 & 山坡 & 463 & 93 & 10 \\
\hline 27 & 44004-11-2-L11-01 & $111^{\circ} 15^{\prime} 08^{\prime \prime}$ & $22^{\circ} 16^{\prime} 18^{\prime \prime}$ & 1,358 & 兽路 & 667 & 30 & 9 \\
\hline 28 & 44004-11-2-L12-01 & $111^{\circ} 14^{\prime} 53^{\prime \prime}$ & $22^{\circ} 15^{\prime} 05^{\prime \prime}$ & 1,287 & 溪边 & 640 & 121 & 11 \\
\hline 29 & 44004-11-2-L13-01 & $111^{\circ} 14^{\prime} 34^{\prime \prime}$ & $22^{\circ} 14^{\prime} 49^{\prime \prime}$ & 1,132 & 溪边 & 601 & 495 & 10 \\
\hline 30 & 44004-11-2-L14-01 & $111^{\circ} 15^{\prime} 01^{\prime \prime}$ & $22^{\circ} 14^{\prime} 34^{\prime \prime}$ & 1,127 & 山脊 & 650 & 277 & 20 \\
\hline 31 & 44004-11-2-M07-01 & $111^{\circ} 15^{\prime} 31^{\prime \prime}$ & $22^{\circ} 17^{\prime} 54^{\prime \prime}$ & 1,274 & 山坡 & 927 & 168 & 15 \\
\hline 32 & 44004-11-2-M08-01 & $111^{\circ} 15^{\prime} 20^{\prime \prime}$ & $22^{\circ} 17^{\prime} 38^{\prime \prime}$ & 1,207 & 常绿、落叶阔叶混交林 & 667 & 279 & 16 \\
\hline 33 & 44004-11-2-M09-01 & $111^{\circ} 15^{\prime} 22^{\prime \prime}$ & $22^{\circ} 17^{\prime} 18^{\prime \prime}$ & 1,154 & 常绿、落叶阔叶混交林 & 813 & 81 & 12 \\
\hline 34 & 44004-11-2-M10-01 & $111^{\circ} 15^{\prime} 09^{\prime \prime}$ & $22^{\circ} 16^{\prime} 32^{\prime \prime}$ & 1,330 & 兽路 & 669 & 95 & 11 \\
\hline 35 & 44004111-2-M11-01 & $111^{\circ} 15^{\prime} 15^{\prime \prime}$ & $22^{\circ} 16^{\prime} 15^{\prime \prime}$ & 1,419 & 兽路 & 774 & 153 & 17 \\
\hline 36 & 44004111-2-M13-01 & $111^{\circ} 14^{\prime} 59^{\prime \prime}$ & $22^{\circ} 14^{\prime} 49^{\prime \prime}$ & 1,399 & 山脊 & 605 & 336 & 18 \\
\hline 37 & 44004111-2-N09-01 & $111^{\circ} 15^{\prime} 43^{\prime \prime}$ & $22^{\circ} 17^{\prime} 12^{\prime \prime}$ & 1,079 & 兽路 & 740 & 60 & 10 \\
\hline 38 & 44004111-2-N10-01 & $111^{\circ} 15^{\prime} 41^{\prime \prime}$ & $22^{\circ} 16^{\prime} 21^{\prime \prime}$ & 1,454 & 山坡 & 590 & 21 & 6 \\
\hline 39 & 44004111-2-N11-01 & $111^{\circ} 15^{\prime} 45^{\prime \prime}$ & $22^{\circ} 16^{\prime} 16^{\prime \prime}$ & 1,460 & 兽路 & 588 & 225 & 14 \\
\hline 40 & 44004111-2-O09-01 & $111^{\circ} 16^{\prime} 55^{\prime \prime}$ & $22^{\circ} 17^{\prime} 17^{\prime \prime}$ & 1,187 & 山坡 & 745 & 80 & 12 \\
\hline 41 & 44004111-2-O10-01 & $111^{\circ} 16^{\prime} 39^{\prime \prime}$ & $22^{\circ} 16^{\prime} 56^{\prime \prime}$ & 1,342 & 山坡 & 915 & 210 & 22 \\
\hline
\end{tabular}


李林妙, 池辉云, 万雅琼, 周佳滨, 张礼标, 何向阳, 黄文忠, 张伯军, 徐湛荣, 刘昌传, 赖任燕, 朱秀芳, 李友余, 李佳琦, 陈金平 (2020) 广东云开山国家级自然保护区鸟兽 红外相机调查初报. 生物多样性, 28, 1154-1159. http://www.biodiversity-science.net/CN/10.17520/biods.2020103

\begin{tabular}{|c|c|c|c|c|c|c|c|c|}
\hline 42 & 44004111-2-O11-01 & $111^{\circ} 16^{\prime} 28^{\prime \prime}$ & $22^{\circ} 16^{\prime} 45^{\prime \prime}$ & 1,425 & 垭口 & 650 & 96 & 17 \\
\hline 43 & 44004111-3-T07-01 & $111^{\circ} 19^{\prime} 28^{\prime \prime}$ & $22^{\circ} 18^{\prime} 26^{\prime \prime}$ & 917 & 山坡 & 615 & 85 & 9 \\
\hline 44 & 44004111-3-T08-01 & $111^{\circ} 19^{\prime} 44^{\prime \prime}$ & $22^{\circ} 17^{\prime} 49^{\prime \prime}$ & 864 & 林间开阔地 & 396 & 275 & 18 \\
\hline 45 & 44004111-3-U07-01 & $111^{\circ} 20^{\prime} 02^{\prime \prime}$ & $22^{\circ} 17^{\prime} 55^{\prime \prime}$ & 1,030 & 山坡 & 433 & 107 & 13 \\
\hline 46 & 44004111-3-U08-01 & $111^{\circ} 20^{\prime} 15^{\prime \prime}$ & $22^{\circ} 17^{\prime} 45^{\prime \prime}$ & 919 & 山坡 & 406 & 6 & 2 \\
\hline 47 & 44004111-3-U09-01 & $111^{\circ} 20^{\prime} 33^{\prime \prime}$ & $22^{\circ} 17^{\prime} 03^{\prime \prime}$ & 1,081 & 垭口 & 426 & 176 & 13 \\
\hline 48 & 44004111-3-V07-01 & $111^{\circ} 20^{\prime} 50^{\prime \prime}$ & $22^{\circ} 18^{\prime} 07^{\prime \prime}$ & 861 & 山坡 & 542 & 31 & 11 \\
\hline 49 & 44004111-3-V08-01 & $111^{\circ} 20^{\prime} 27^{\prime \prime}$ & $22^{\circ} 17^{\prime} 56^{\prime \prime}$ & 985 & 林间开阔地 & 371 & 167 & 12 \\
\hline 50 & 44004111-3-V09-01 & $111^{\circ} 21^{\prime} 23^{\prime \prime}$ & $22^{\circ} 17^{\prime} 40^{\prime \prime}$ & 1,230 & 垭口 & 439 & 117 & 9 \\
\hline 51 & 44004111-3-W07-01 & $111^{\circ} 20^{\prime} 37^{\prime \prime}$ & $22^{\circ} 18^{\prime} 06^{\prime \prime}$ & 884 & 山脊 & 184 & 75 & 7 \\
\hline 52 & 44004111-3-W08-01 & $111^{\circ} 20^{\prime} 30^{\prime \prime}$ & $22^{\circ} 17^{\prime} 21^{\prime \prime}$ & 1,161 & 垭口 & 427 & 114 & 14 \\
\hline 53 & 44004111-3-W09-01 & $111^{\circ} 20^{\prime} 43^{\prime \prime}$ & $22^{\circ} 16^{\prime} 43^{\prime \prime}$ & 963 & 常绿、落叶阔叶混交林 & 499 & 127 & 10 \\
\hline 54 & 44004111-3-W10-01 & $111^{\circ} 21^{\prime} 31^{\prime \prime}$ & $22^{\circ} 16^{\prime} 55^{\prime \prime}$ & 997 & 常绿、落叶阔叶混交林 & 446 & 93 & 11 \\
\hline 55 & 44004111-3-X07-01 & $111^{\circ} 21^{\prime} 43^{\prime \prime}$ & $22^{\circ} 17^{\prime} 43^{\prime \prime}$ & 1,232 & 垭口 & 335 & 45 & 5 \\
\hline 56 & 44004111-3-X08-01 & $111^{\circ} 21^{\prime} 53^{\prime \prime}$ & $22^{\circ} 17^{\prime} 55^{\prime \prime}$ & 1,150 & 溪边 & 491 & 48 & 10 \\
\hline 57 & 44004111-3-X09-01 & $111^{\circ} 22^{\prime} 0^{\prime \prime}$ & $22^{\circ} 17^{\prime} 20^{\prime \prime}$ & 1,151 & 山坡 & 438 & 83 & 8 \\
\hline 58 & 44004111-3-X10-01 & $111^{\circ} 21^{\prime} 47^{\prime \prime}$ & $22^{\circ} 16^{\prime} 42^{\prime \prime}$ & 967 & 垭口 & 574 & 539 & 23 \\
\hline 59 & 44004111-3-X11-01 & $111^{\circ} 21^{\prime} 27^{\prime \prime}$ & $22^{\circ} 16^{\prime} 18^{\prime \prime}$ & 903 & 山坡 & 608 & 7 & 3 \\
\hline 60 & 44004111-3-Y11-01 & $111^{\circ} 22^{\prime} 26^{\prime \prime}$ & $22^{\circ} 16^{\prime} 16^{\prime \prime}$ & 829 & 山脊 & 626 & 62 & 7 \\
\hline 61 & 44004111-3-Y12-01 & $111^{\circ} 22^{\prime} 17^{\prime \prime}$ & $22^{\circ} 15^{\prime} 12^{\prime \prime}$ & 1,035 & 常绿、落叶阔叶混交林 & 651 & 79 & 12 \\
\hline
\end{tabular}


李林妙, 池辉云, 万雅琼, 周佳滨, 张礼标, 何向阳, 黄文忠, 张伯军, 徐湛荣, 刘昌传, 赖任燕, 朱秀芳, 李友余, 李佳琦, 陈金平 (2020) 广东云开山国家级自然保护区鸟兽 红外相机调查初报. 生物多样性, 28, 1154-1159. http://www.biodiversity-science.net/CN/10.17520/biods.2020103

附录2 广东云开山国家级自然保护区红外相机调查记录到的兽类和鸟类物种名录

Appendix 2 The list of mammals and birds captured by camera-trapping in the Guangdong Yunkaishan National Nature Reserve

\begin{tabular}{|c|c|c|c|c|c|c|}
\hline $\begin{array}{l}\text { 物种 } \\
\text { Species }\end{array}$ & $\begin{array}{l}\text { IUCN红色名录 } \\
\text { IUCN Red List }\end{array}$ & $\begin{array}{c}\text { 中国脊椎动物红 } \\
\text { 色名录 } \\
\text { Red List of } \\
\text { China's } \\
\text { Vertebrates }\end{array}$ & $\begin{array}{c}\text { 保护级别 Protection } \\
\text { level }\end{array}$ & $\begin{array}{c}\text { 拍摄位点数 Number of } \\
\text { camera sites }\end{array}$ & $\begin{array}{c}\text { 独立照片数 } \\
\text { Number of } \\
\text { independent } \\
\text { images }\end{array}$ & $\begin{array}{c}\text { 相对多度指数 } \\
\text { RAI }\end{array}$ \\
\hline \multicolumn{7}{|l|}{ I 哺乳纲 Mammalia } \\
\hline \multicolumn{7}{|l|}{ 一、偶蹄目 Cetartiodactyla } \\
\hline \multicolumn{7}{|l|}{ (一)鹿科 Cervidae } \\
\hline 1. 赤麇 Muntiacus vaginalis & LC & NT & & 49 & 569 & 1.51 \\
\hline \multicolumn{7}{|l|}{ (二)猪科 Suidae } \\
\hline 2. 野猪 Sus scrofa & LC & LC & & 43 & 299 & 0.79 \\
\hline \multicolumn{7}{|l|}{ 二、食肉目 Carnivora } \\
\hline \multicolumn{7}{|l|}{ (三)灵猫科 Viverridae } \\
\hline 3. 果子狸 Paguma larvata & LC & NT & & 36 & 100 & 0.27 \\
\hline \multicolumn{7}{|l|}{ (四)猫科 Felidae } \\
\hline 4. 豹猫 Prionailurus bengalensis & LC & $\mathrm{VU}$ & & 35 & 86 & 0.23 \\
\hline \multicolumn{7}{|l|}{ 三、啮齿目 Rodentia } \\
\hline \multicolumn{7}{|l|}{ (五)叟科 Mustelidae } \\
\hline 5. 叟獾 Melogale moschata & LC & NT & & 51 & 566 & 1.50 \\
\hline 6. 黄腹鼬 Mustela kathiah & LC & NT & & 14 & 24 & 0.06 \\
\hline \multicolumn{7}{|l|}{ (六)松鼠科 Sciuridae } \\
\hline 7. 赤腹松鼠 Callosciurus erythraeus & LC & LC & & 57 & 606 & 1.61 \\
\hline \multicolumn{7}{|l|}{ 8. 红腿长吻松鼠 } \\
\hline Dremomys pyrrhomerus & LC & NT & & 11 & 36 & 0.10 \\
\hline 四、树獡目 Scandentia & & & & & & \\
\hline
\end{tabular}


李林妙, 池辉云, 万雅琼, 周佳滨, 张礼标, 何向阳, 黄文忠, 张伯军, 徐湛荣, 刘昌传, 赖任燕, 朱秀芳, 李友余, 李佳琦, 陈金平 (2020) 广东云开山国家级自然保护区鸟兽 红外相机调查初报. 生物多样性, 28, 1154-1159. http://www.biodiversity-science.net/CN/10.17520/biods.2020103

\begin{tabular}{|c|c|c|c|c|c|c|}
\hline $\begin{array}{l}\text { 物种 } \\
\text { Species }\end{array}$ & $\begin{array}{l}\text { IUCN红色名录 } \\
\text { IUCN Red List }\end{array}$ & $\begin{array}{c}\text { 中国脊椎动物红 } \\
\text { 色名录 } \\
\text { Red List of } \\
\text { China's } \\
\text { Vertebrates }\end{array}$ & $\begin{array}{c}\text { 保护级别 Protection } \\
\text { level }\end{array}$ & $\begin{array}{c}\text { 拍摄位点数 Number of } \\
\text { camera sites }\end{array}$ & $\begin{array}{c}\text { 独立照片数 } \\
\text { Number of } \\
\text { independent } \\
\text { images }\end{array}$ & $\begin{array}{c}\text { 相对多度指数 } \\
\text { RAI }\end{array}$ \\
\hline \multicolumn{7}{|l|}{ (七)树塪科 Tupaiidae } \\
\hline 9. 北树舄 Tupaia belangeri & LC & $\mathrm{LC}$ & & 24 & 85 & 0.23 \\
\hline \multicolumn{7}{|l|}{ (八)家畜 Livestock } \\
\hline 家牛 Bos taurus & & & & 30 & 678 & 1.80 \\
\hline 家羊 Capra aegagrus hirsus & & & & 3 & 12 & 0.03 \\
\hline (九)人类 Homo sapiens & & & & 36 & 113 & 0.30 \\
\hline \multicolumn{7}{|l|}{ II 鸟纲 Aves } \\
\hline \multicolumn{7}{|l|}{ 五、鸡形目 Galliformes } \\
\hline \multicolumn{7}{|l|}{ (八)雉科 Phasianidae } \\
\hline 10. 原鸡 Gallus gallus & LC & NT & II & 14 & 22 & 0.06 \\
\hline 11. 灰胸竹鸡 Bambusicola thoracica & LC & LC & & 3 & 6 & 0.02 \\
\hline 12. 白鹏 Lophura nycthemera & LC & LC & II & 3 & 3 & 0.01 \\
\hline 13. 中华鹧扸 Francolinus pintadeanus & LC & NT & & 3 & 6 & 0.02 \\
\hline \multicolumn{7}{|l|}{$\begin{array}{l}\text { 六、鸭形目 Charadriiformes } \\
\text { (九)㛚科 Scolopacidae }\end{array}$} \\
\hline 14. 丘斛 Scolopax rusticola & LC & LC & & 9 & 30 & 0.08 \\
\hline \multicolumn{7}{|l|}{ (十)鸭铇科 Columbidae } \\
\hline 15. 珠颈斑扸 Streptopelia chinensis & LC & LC & & 3 & 3 & 0.01 \\
\hline 16. 绿翅金扸 Chalcophaps indica & $\mathrm{vU}$ & LC & & 1 & 1 & 0.00 \\
\hline \multicolumn{7}{|l|}{ 七、隼形目 Falconiformes } \\
\hline \multicolumn{7}{|l|}{ (十一)鹰科 Accipitridae } \\
\hline 17. 雀鹰 Accipiter nisus & LC & LC & & 2 & 2 & 0.01 \\
\hline 八、雀形目 Passeriformes & & & & & & \\
\hline
\end{tabular}


李林妙, 池辉云, 万雅琼, 周佳滨, 张礼标, 何向阳, 黄文忠, 张伯军, 徐湛荣, 刘昌传, 赖任燕, 朱秀芳, 李友余, 李佳琦, 陈金平 (2020) 广东云开山国家级自然保护区鸟兽 红外相机调查初报. 生物多样性, 28, 1154-1159. http://www.biodiversity-science.net/CN/10.17520/biods.2020103

\begin{tabular}{|c|c|c|c|c|c|c|}
\hline $\begin{array}{c}\text { 物种 } \\
\text { Species }\end{array}$ & $\begin{array}{l}\text { IUCN红色名录 } \\
\text { IUCN Red List }\end{array}$ & $\begin{array}{c}\text { 中国脊椎动物红 } \\
\text { 色名录 } \\
\text { Red List of } \\
\text { China's } \\
\text { Vertebrates }\end{array}$ & $\begin{array}{c}\text { 保护级别 Protection } \\
\text { level }\end{array}$ & $\begin{array}{c}\text { 拍摄位点数 Number of } \\
\text { camera sites }\end{array}$ & $\begin{array}{l}\text { 独立照片数 } \\
\text { Number of } \\
\text { independent } \\
\text { images }\end{array}$ & $\begin{array}{c}\text { 相对多度指数 } \\
\text { RAI }\end{array}$ \\
\hline \multicolumn{7}{|l|}{ (十二)冻科 Turdidae } \\
\hline 18. 橙头地鸫 Zoothera citrina & LC & LC & & 16 & 62 & 0.16 \\
\hline 19. 虎斑地鸫 Zoothera dauma & LC & LC & & 37 & 370 & 0.98 \\
\hline 20. 乌冻 Turdus merula & LC & $\mathrm{LC}$ & & 11 & 34 & 0.09 \\
\hline 21. 灰背鸫 Turdus hortulorum & & $\mathrm{LC}$ & & 7 & 24 & 0.06 \\
\hline 22. 乌灰鸫 Turdus cardis & $\mathrm{LC}$ & $\mathrm{LC}$ & & 1 & 1 & 0.00 \\
\hline 23. 紫啸鸫 Myiophoneus caeruleus & LC & $\mathrm{LC}$ & & 27 & 515 & 1.37 \\
\hline 24. 蓝歌鸲 Luscinia cyane & LC & $\mathrm{LC}$ & & 1 & 1 & 0.00 \\
\hline \multicolumn{7}{|l|}{ (十三)㰸科 Muscicapidae } \\
\hline 25. 白尾蓝仙䳜 Cyornis concretus & LC & LC & & 10 & 35 & 0.09 \\
\hline 26. 大仙䳜 Niltava grandis & LC & LC & & 1 & 1 & 0.00 \\
\hline \multicolumn{7}{|l|}{ (十四)鸦科 Corvidae } \\
\hline 27. 蓝绿鹊 Cissa chinensis & LC & NT & & 2 & 2 & 0.01 \\
\hline 28. 红嘴蓝鹊 Urocissa erythrorhyncha & LC & LC & & 4 & 8 & 0.02 \\
\hline 29. 松鸦 Garrulus glandarius & LC & LC & & 1 & 1 & 0.00 \\
\hline \multicolumn{7}{|l|}{ (十五)画眉科 Timaliidae } \\
\hline 30. 红嘴相思鸟 Leiothrix lutea & LC & LC & & 29 & 334 & 0.89 \\
\hline \multicolumn{7}{|l|}{ 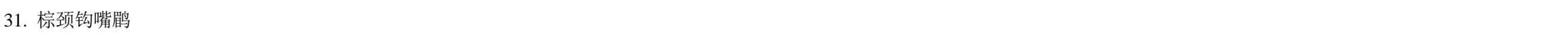 } \\
\hline Pomatorhinus ruficollis & LC & LC & & 10 & 13 & 0.03 \\
\hline 32. 画眉 Garrulax canorus & LC & NT & & 2 & 10 & 0.03 \\
\hline 33. 红尾噪鹋 Garrulax milnei & LC & LC & & 1 & 1 & 0.00 \\
\hline 34. 黑喉噪鹋 Garrulax chinensis & LC & LC & & 6 & 11 & 0.03 \\
\hline 35. 黑领噪鹋 Garrulax pectoralis & LC & LC & & 14 & 38 & 0.10 \\
\hline
\end{tabular}


李林妙, 池辉云, 万雅琼, 周佳滨, 张礼标, 何向阳, 黄文忠, 张伯军, 徐湛荣, 刘昌传, 赖任燕, 朱秀芳, 李友余, 李佳琦, 陈金平 (2020) 广东云开山国家级自然保护区鸟兽 红外相机调查初报. 生物多样性, 28, 1154-1159. http://www.biodiversity-science.net/CN/10.17520/biods.2020103

\begin{tabular}{|c|c|c|c|c|c|c|}
\hline $\begin{array}{c}\text { 物种 } \\
\text { Species }\end{array}$ & $\begin{array}{l}\text { IUCN红色名录 } \\
\text { IUCN Red List }\end{array}$ & $\begin{array}{c}\text { 中国脊椎动物红 } \\
\text { 色名录 } \\
\text { Red List of } \\
\text { China's } \\
\text { Vertebrates }\end{array}$ & $\begin{array}{c}\text { 保护级别 Protection } \\
\text { level }\end{array}$ & $\begin{array}{c}\text { 拍摄位点数 Number of } \\
\text { camera sites }\end{array}$ & $\begin{array}{l}\text { 独立照片数 } \\
\text { Number of } \\
\text { independent } \\
\text { images }\end{array}$ & $\begin{array}{c}\text { 相对多度指数 } \\
\text { RAI }\end{array}$ \\
\hline 36. 褐胸噪鹛 Garrulax maesi & $\mathrm{LC}$ & $\mathrm{LC}$ & & 2 & 7 & 0.02 \\
\hline (十六)绣眼鸟科 Zosteropidae & & & & & & 0.00 \\
\hline $\begin{array}{l}\text { 37. 暗绿绣眼鸟 Zosterops japonicus } \\
\text { (十七)莺科 Sylviidae }\end{array}$ & $\mathrm{LC}$ & $\mathrm{LC}$ & & 4 & 11 & 0.03 \\
\hline 38. 长尾缝叶莺 Orthotomus sutorius & $\mathrm{LC}$ & $\mathrm{LC}$ & & 1 & 1 & 0.00 \\
\hline $\begin{array}{l}\text { 39. 黑眉柳莺 Phylloscopus ricketti } \\
\text { (十八)雀科 Passeridae }\end{array}$ & $\mathrm{LC}$ & $\mathrm{LC}$ & & 2 & 2 & 0.01 \\
\hline $\begin{array}{l}\text { 40. 麻雀 Passer montanus } \\
\text { (十九)卷尾科 Dicruridae }\end{array}$ & LC & $\mathrm{LC}$ & & 1 & 1 & 0.00 \\
\hline $\begin{array}{l}\text { 41. 黑卷尾 Dicrurus macrocercus } \\
\text { 九、鹃形目 Cuculiformes } \\
\text { (二十)杜鹃科 Cuculidae }\end{array}$ & $\mathrm{LC}$ & LC & & 1 & 1 & 0.00 \\
\hline $\begin{array}{l}\text { 42. 大鹰鹃 Hierococcyx sparverioides } \\
\text { 十、鹳形目 Ciconiiformes } \\
\text { (二十一)鹭科 Ardeidae }\end{array}$ & $\mathrm{LC}$ & LC & & 2 & 6 & 0.02 \\
\hline 43. 黑冠鳽 Gorsachius melanolophus & LC & NT & & 1 & 3 & 0.01 \\
\hline
\end{tabular}

VU: 易危; NT: 近危; LC: 无危 
李林妙, 池辉云, 万雅琼, 周佳滨, 张礼标, 何向阳, 黄文忠, 张伯军, 徐湛荣, 刘昌传, 赖任燕, 朱秀芳, 李友余, 李佳琦, 陈金平 (2020) 广东云开山国家级自然保护区鸟兽 红外相机调查初报. 生物多样性, 28, 1154-1159. http://www.biodiversity-science.net/CN/10.17520/biods.2020103

附录3 广东云开山国家级自然保护区红外相机调查中记录到的部分兽类和鸟类物种照片

Appendix 3 Photographs of mammal and bird species recorded by the camera-trapping in the Guangdong Yunkaishan National Nature Reserve

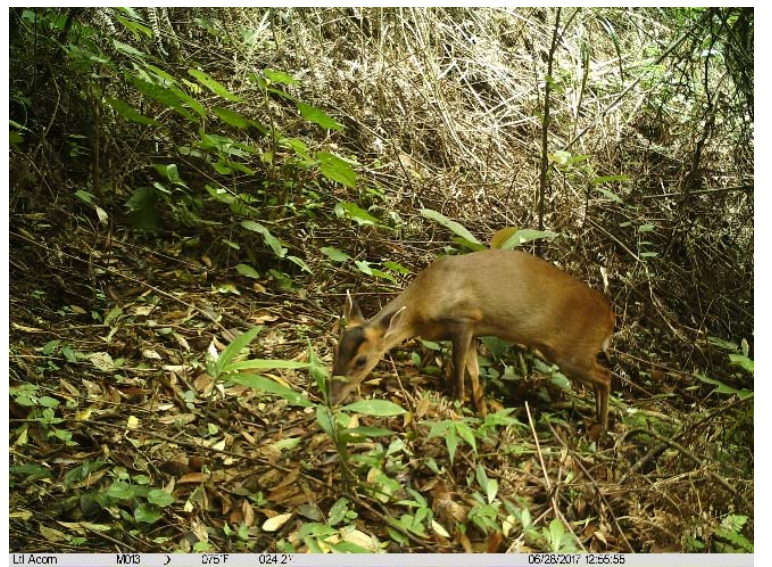

赤鹿 Muntiacus vaginalis

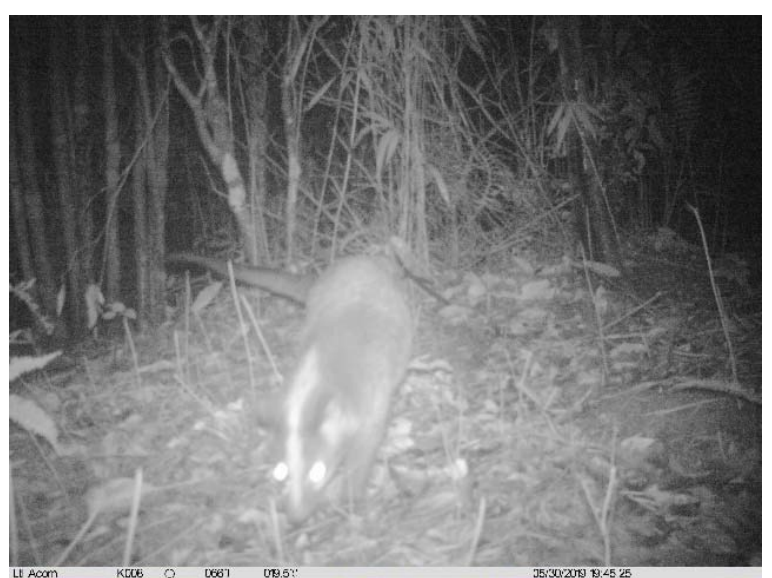

果子狸 Paguma larvata

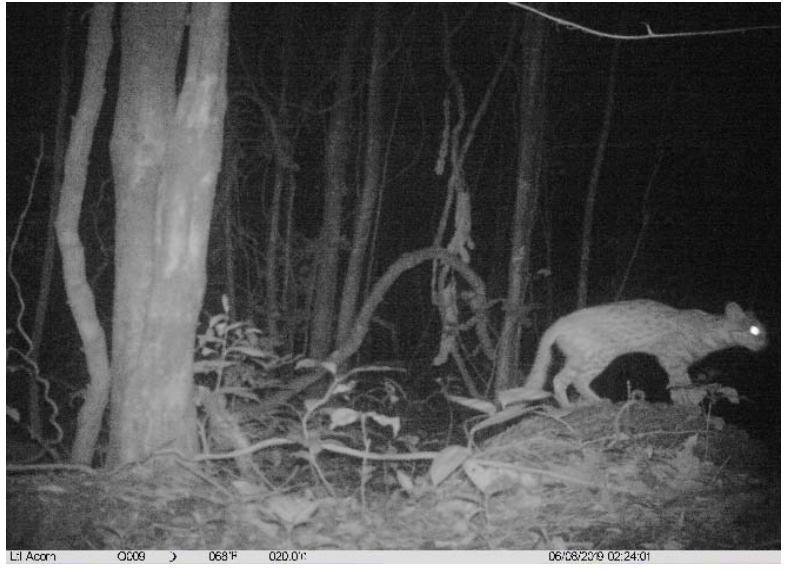

豹猫 Prionailurus bengalensis

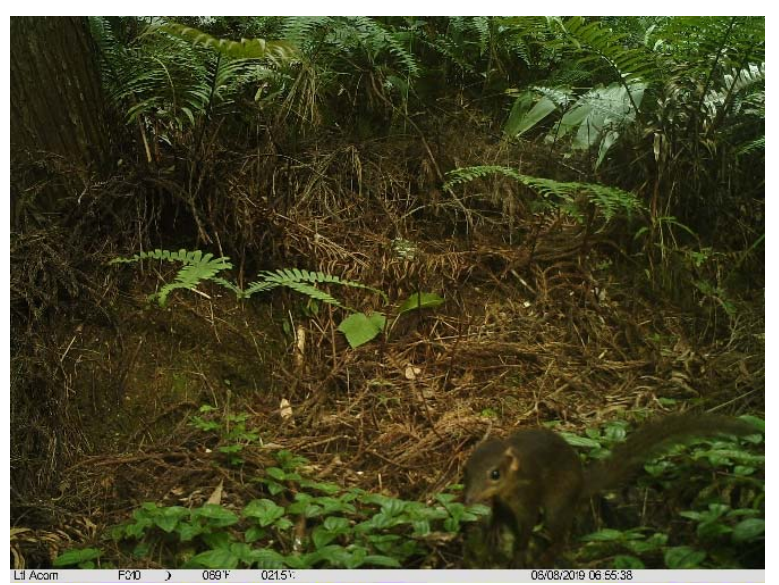

北树鼠 Tupaia belangeri

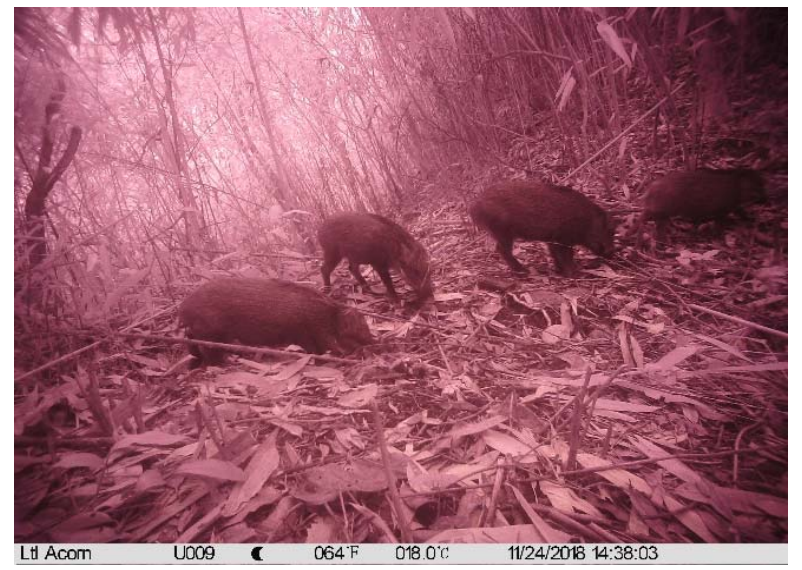

野猪 Sus scrofa

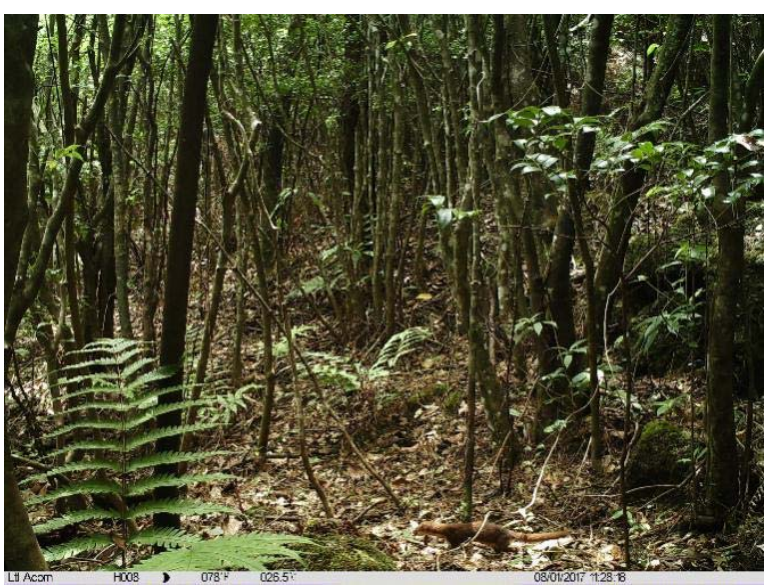

黄腹鼠由 Mustela kathiah 
李林妙, 池辉云, 万雅琼, 周佳滨, 张礼标, 何向阳, 黄文忠, 张伯军, 徐湛荣, 刘昌传, 赖任燕, 朱秀芳, 李友余, 李佳琦, 陈金平 (2020) 广东云开山国家级自然保护区鸟兽 红外相机调查初报. 生物多样性, 28, 1154-1159. http://www.biodiversity-science.net/CN/10.17520/biods.2020103

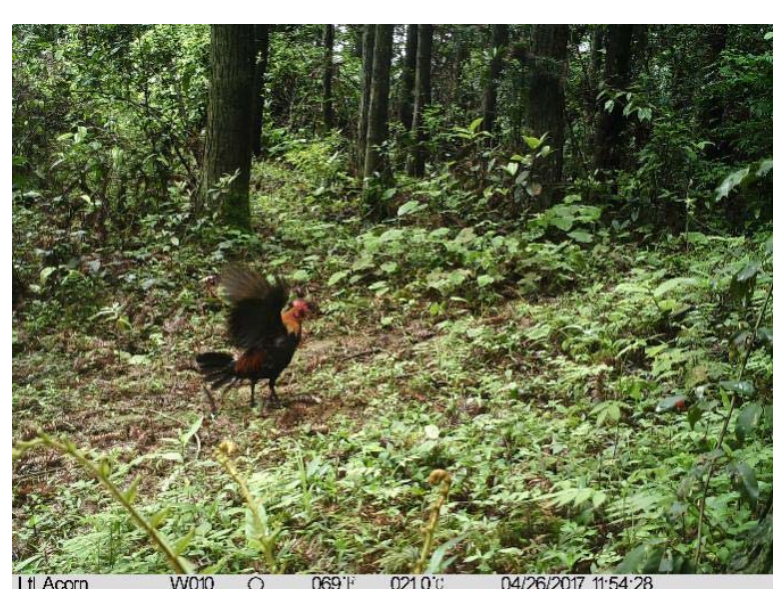

原鸡 Gallus gallus

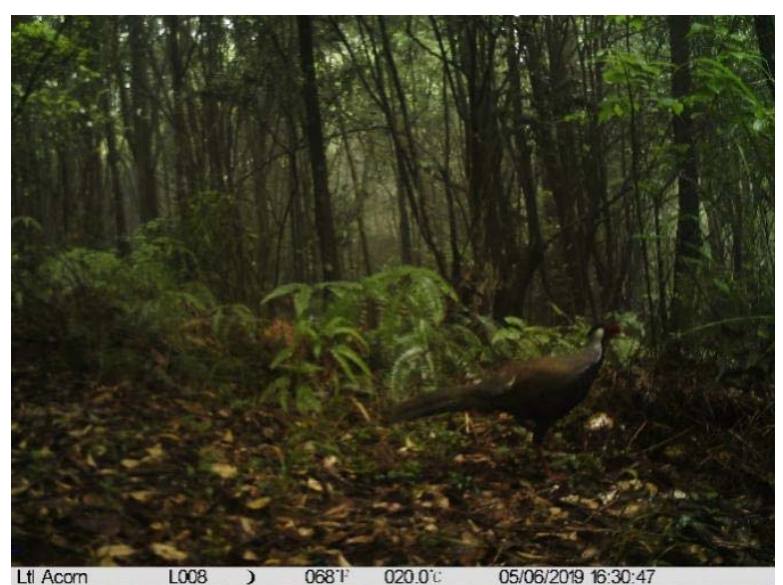

白酠 Lophura nycthemera

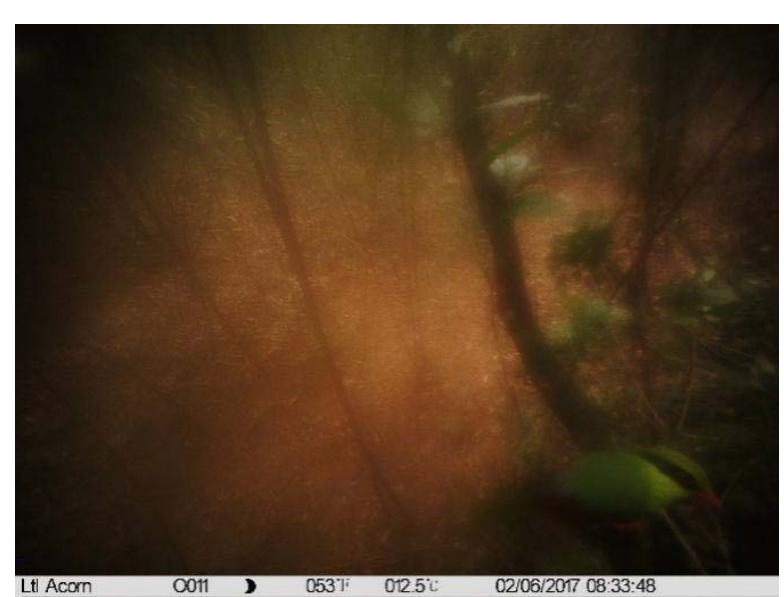

蓝绿鹊 Cissa chinensis

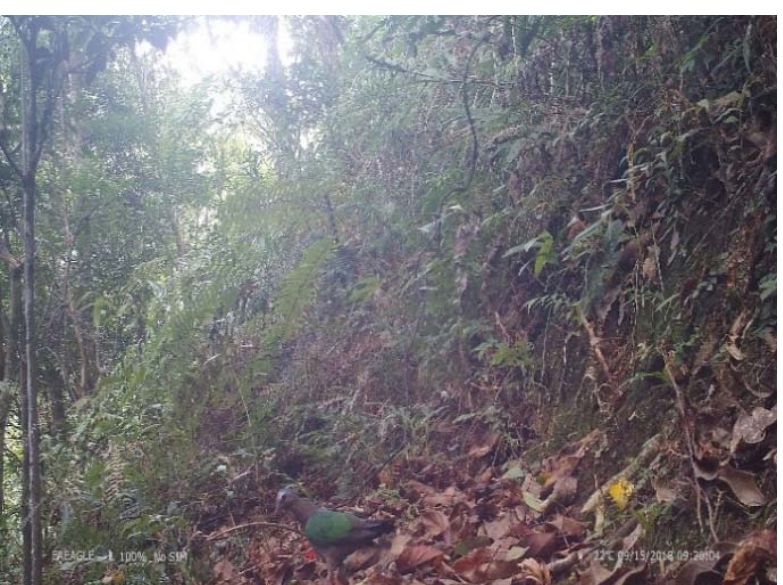

绿翅金鸠 Chalcophaps indica

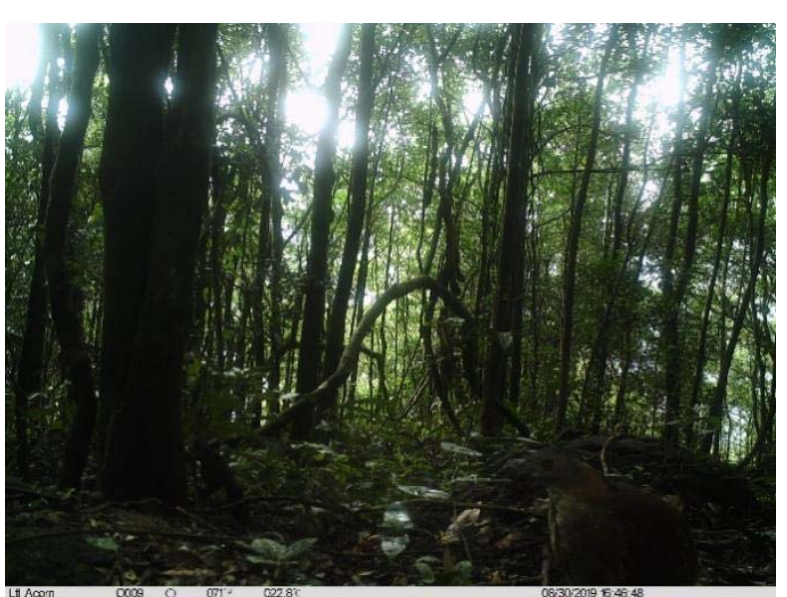

黑冠鳽 Gorsachius melanolophus

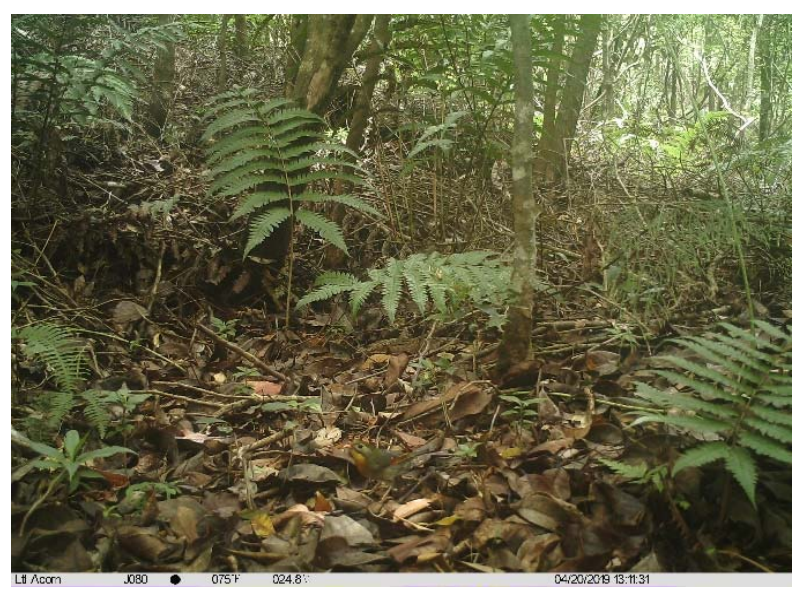

红嘴相思鸟 Leiothrix lutea 